\title{
Three new species of the genus Rhyzobius Stephens, 1829 from New Guinea (Coleoptera: Coccinellidae: Coccidulini)
}

\author{
Tomasz CZERWIŃSKI I. ${ }^{1 *}$, Karol SZAWARYN ${ }^{2} \&$ Wioletta TOMASZEWSKA ${ }^{3}$ \\ 1,2,3 Museum and Institute of Zoology, Polish Academy of Sciences, Wilcza 64, \\ 00-679 Warszawa, Poland. \\ ${ }^{1}$ Corresponding author: tczerwinski@miiz.waw.pl \\ ${ }^{2}$ Email: k.szawaryn@gmail.com \\ ${ }^{3}$ Email: wiolkat@miiz.waw.pl \\ ${ }^{1}$ urn:1sid:zoobank.org:author:B7AF2729-3590-48B3-A065-7825623EF8B3 \\ ${ }^{2}$ urn:lsid:zoobank.org:author:D741C759-6CDD-4B61-BE93-3ECC2918A73F \\ ${ }^{3}$ urn:1sid:zoobank.org:author:F2A77E2D-E0FF-45F8-8035-B49DC1418F99
}

\begin{abstract}
Three new Papuan species of the ladybird genus Rhyzobius Stephens, Rhyzobius albinos sp. nov., $R$. atramentarius sp. nov. and $R$. serratus sp. nov., are described, diagnosed and illustrated. An updated key to species of Rhyzobius from New Guinea is provided.
\end{abstract}

Keywords. Coccinelloidea, Papua New Guinea, Mount Wilhelm, new species.

Czerwiński T., Szawaryn K. \& Tomaszewska W. 2020. Three new species of the genus Rhyzobius Stephens, 1829 from New Guinea (Coleoptera: Coccinellidae: Coccidulini). European Journal of Taxonomy 692: 1-17. https://doi.org/10.5852/ejt.2020.692

\section{Introduction}

The family Coccinellidae Latreille, 1807, with bright colouration in most of the species, is one of the best recognized groups of beetles. With over 6000 species, it is the largest beetle family within the superfamily Coccinelloidea Latreille, 1807 (Robertson et al. 2015).

The position of the genus Rhyzobius Stephens, 1829 within the family Coccinellidae has changed over the decades. Stephens (1829), while establishing the genus, placed it close to Scymnus Kugelann, 1794 in an informal group called "Pubescentes". Mulsant (1850) in his monograph of Coccinellidae, transferred this genus to the subfamily Scymninae Mulsant, 1846 (Scymniens), containing mostly hairy species. Subsequently, it was classified within the subfamily Rhizobiinae Crotch, 1874 (Rhizobiides) (Crotch 1874), tribe Coccidulini Mulsant, 1846 (Ganglbauer 1899) or tribe Rhizobiini (Casey 1899). Currently Rhyzobius is classified within the tribe Coccidulini of the subfamily Coccinellinae Latreille, 1807, one of the two coccinellid subfamilies recognized by Ślipiński (2007). Seago et al. (2011) in their research based on molecular and morphological data, confirmed the position of Rhyzobius within the subfamily Coccinellinae although they indicated the polyphyletic character of this taxon, e.g., Australian and 
European species of this genus used in the analysis were placed in separate, distant clades on the tree. This indicates a need for a thorough phylogenetic study of the group.

Rhyzobius in the present sense is a cosmopolitan group, but most species are distributed in tropical and subtropical regions of the Old World with the highest diversity in Australia (Tomaszewska 2010). They are known to be primarily coccid feeders (Tomaszewska 2010). The New Guinean fauna was represented until the present study by 11 species, including Rhyzobius amabilis Weise, 1917 and 10 species described by Tomaszewska (2010) in her taxonomic revision of Rhyzobius.

The insect fauna of New Guinea is species rich, but ladybird beetles (Coccinellidae) from this region remain little known. In recent years, numerous new coccinellid species have been described from this island (Poorani \& Ślipiński 2009, 2010; Poorani et al. 2014; Szawaryn 2018), and many more will potentially be discovered. When studying material collected during the "Our Planet Reviewed - Papua New Guinea" project, three new species of Rhyzobius were discovered and are described here. A key to the New Guinean species of the genus is also updated.

\section{Material and methods}

The specimens examined were collected during the project "Our Planet Reviewed IBISCA Niugini 2012-2013" (Leponce et al. 2016) in Wanang Station and along a West-East transect on the slopes of Mount Wilhelm in Papua New Guinea. They are kept in the Muséum national d'histoire naturelle in Paris (MNHN) and the Museum and Institute of Zoology, Polish Academy of Sciences (MIZ).

Genitalia were dissected, cleared in a $10 \% \mathrm{KOH}$ solution, and placed in glycerol on slides for further study. Measurements were recorded as follows: total body length (TL), from apical margin of clypeus to apex of elytra; width (EW), across both elytra in the widest part; pronotal length (PL), from the middle of anterior margin to margin of basal foramen; pronotal width (PW), across widest part; elytral length (EL), along suture including scutellum. All colour images were taken using a stereo microscope Leica MZ 16 with a digital camera IC 3D; final images were produced using Helicon Focus 5.0X64 and Adobe ${ }^{\circledR}$ Photoshop CS6 software. The SEM photographs were taken in the Laboratory of Scanning Microscopy, MIZ (Warsaw), using a scanning electron microscope HITACHI S-3400N under low vacuum conditions. Terminology used for morphology follows Ślipiński (2007) and Ślipiński \& Tomaszewska (2010).

\section{Results}

\section{Taxonomy}

Order Coleoptera Linnaeus, 1758

Superfamily Coccinelloidea Latreille, 1807

Family Coccinellidae Latreille, 1807

Subfamily Coccinellinae, Latreille, 1807

Tribe Coccidulini Mulsant, 1846

Genus Rhyzobius Stephens, 1829

Rhyzobius albinos sp. nov. urn:1sid:zoobank.org:act:BA648A58-DE41-49CE-B3DA-F7D06F2E868C

Figs $1 \mathrm{~A}-\mathrm{D}, 2 \mathrm{~A}-\mathrm{I}, 4 \mathrm{~A}-\mathrm{C}, 5 \mathrm{~A}-\mathrm{D}$

\section{Diagnosis}

This species is most similar to $R$. poorani Tomaszewska, 2010 and $R$. jaya Tomaszewska, 2010 in body colouration. However, $R$. albinos sp. nov. differs from $R$. poorani by having simple, not swollen 
pronotal anterior corners and a prosternal process with complete lateral carinae, joined anteriorly in the form of a triangle. Rhyzobius jaya has a smooth prosternal process without carinae, and straight ventral antennal grooves reaching beyond the posterior margin of the eyes, whereas $R$. albinos sp. nov. has ventral antennal grooves distinctly circularly bent towards the outer margin of the eyes. From all other New Guinean species of Rhyzobius, R. albinos sp. nov. can be distinguished by the bright, almost white ventral body surface, excluding meso- and metaventrite.

\section{Etymology}

The specific epithet is a noun in apposition, it means 'albino' in Polish and refers to the bright colouration of most of the ventral surfaces, not observed in other species of Rhyzobius.

\section{Material examined}

\section{Holotype}

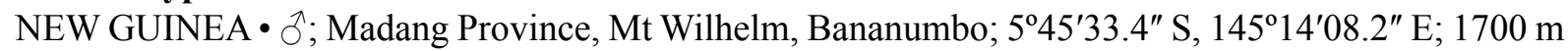
a.s.l.; 9-11 Nov. 2012; “06686-CoCocc Ibisca Niugini 2012”; FIT-MW1700-O-8/8-d16; plot 15, order $17260 ;$ MNHN.

\section{Paratypes}

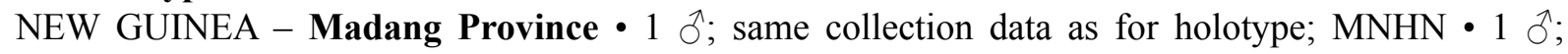
Mt Wilhelm; 2200 m a.s.1.; 18-20 Oct. 2012; "04064-CoCocc Ibisca Niugini 2012"; FIT-MW2200-C2/8-d03; plot 3, order 1603; MNHN • 1 o'; Mt Wilhelm; 2200 m a.s.1.; 19-21 Oct. 2012; "09588-CoCocc Ibisca Niugini 2012"; FIT-MW2200-C-2/8-d04; plot 11, order 6111; MNHN • 1 đో; Mt Wilhelm; $1200 \mathrm{~m}$ a.s.1.; 29-31 Oct. 2012; "16881-CoCocc Ibisca Niugini 2012"; FIT-MW1200-J-3/8-d05; plot 10, order 6033; MNHN • 1 今 ; Mt Wilhelm; 1700 m a.s.1.; 27-29 Oct. 2012; "P1927-CoCocc Ibisca Niugini 2012”; FIT-MW1700-G-2/8-d03; plot 7, order 18341; MNHN - 1 ô; Mt Wilhelm; 2200 m a.s.1.; 20-22 Oct. 2012; "P2334-CoCocc Ibisca Niugini 2012"; FIT-MW2200-I-3/8-d05; plot 9, order 18623; MNHN • 1 今ं; Mt Wilhelm; 1700 m a.s.1.; 9-11 Nov. 2012; "06696-CoCocc Ibisca Niugini 2012"; FIT-MW1700S-8/8-d16; plot 19, order 5202; MIZ • 1 今ं; Mt Wilhelm; 2200 m a.s.1.; 27-29 Oct. 2012; "02308-CoCocc Ibisca Niugini 2012"; FIT-MW2200-N-6/8-d12; plot 14, order 1630; MIZ • 1 đ; ; Wilhelm; $2200 \mathrm{~m}$ a.s.1.; 20-22 Nov. 2012; "P2294-CoCocc Ibisca Niugini 2012”; FIT-MW2200-D-3/8-d05; plot 4, order 18478; MIZ.

\section{Type locality}

Papua New Guinea, Madang Province, Mt Wilhelm, Bananumbo.

\section{Description}

MEAsurements. Length $2.00-2.25 \mathrm{~mm}$; TL/EW $=1.42-1.50 ; \mathrm{PL} / \mathrm{PW}=0.52-0.56$; EL/EW $=1.06-1.07$.

Body (Figs 1A-C, 2A). Moderately oval and convex dorsally, winged; with antennae, mouthparts, hypomera, apex of elytra, most of abdominal ventrites and legs except coxae whitish; frons, anterior and lateral margins of pronotum, preapical parts of elytra, prosternum, epipleura, coxae and partially abdominal ventrite 1 pale brown; vertex, posterior and central parts of pronotum, most of elytra, meso- and metaventrite blackish or dark brown. Elytra with weak bluish, metallic sheen. Dorsum with moderately long and uniform pubescence, not forming pattern on elytra. Elytral bristles absent.

Head (Fig. 1D). Dorsally exposed with eyes almost entirely visible; ventral antennal grooves distinctly circularly bent towards outer margin of eye; corpotentorium absent. Eyes dorsally with inner orbits arcuate, closest at middle; ocular canthus distinct; interocular distance 0.50-0.52 times as wide as head across eyes; interfacetal setae distinct. Antenna (Fig. 2B) 0.77-0.80 times as long as head capsule width, 

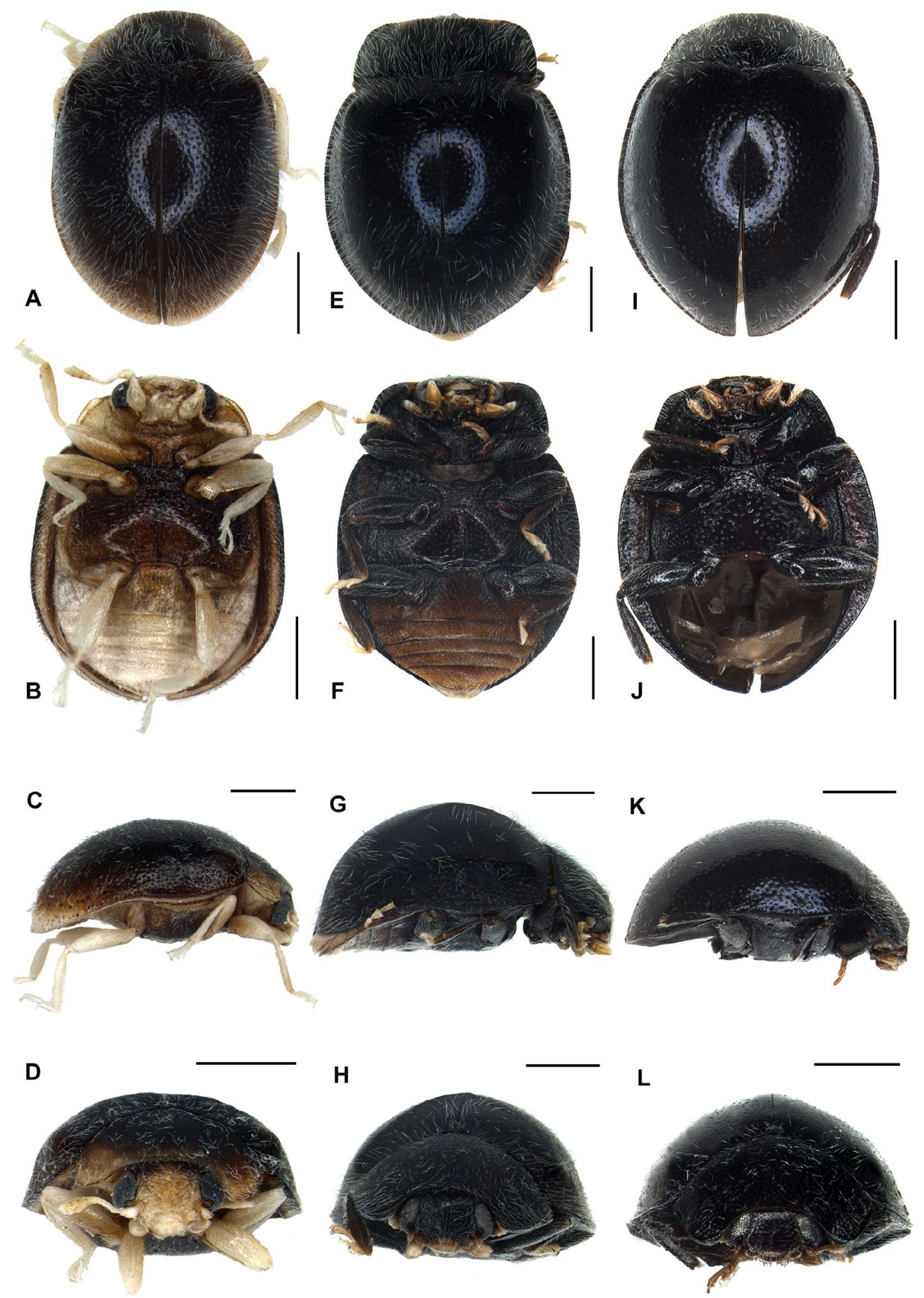

Fig. 1. Habitus of new species of Rhyzobius spp. (holotypes). A-D. R. albinos sp. nov., $\widehat{\partial}$ (MNHN). E-H. R. atramentarius sp. nov., $\widehat{\partial}(\mathrm{MNHN})$. I-L. R. serratus sp. nov., $\precsim(\mathrm{MNHN})$. A, E, I. Dorsal view. $\mathbf{B}, \mathbf{F}, \mathbf{J}$. Ventral view. C, G, K. Lateral view. D, H, L. Frontal view. Scale bars $=0.5 \mathrm{~mm}$. 
composed of 11 antennomeres; scape 1.65-1.70 times as long as pedicel; pedicel narrower than scape, barrel-shaped, 1.25-1.28 times as long as wide; antennomere 3 about 2.5 times longer than wide, and 2.15-2.30 times as long as antennomere 4; antennomere 4 as long as 5; antennomeres 6 and 7 quadrate. Antennal club consisting of 3 antennomeres, with two subterminal segments asymmetrical; penultimate antennomere as long as terminal one; terminal antennomere rounded apically. Anterior clypeal margin (Fig. 2E) distinctly emarginate with rounded lateral lobes and median area membranous. Labrum truncate at apex. Maxillary cardo transverse with outer angle reaching slightly outside of mouth cavity; terminal palpomere 1.30-1.35 times as long as wide, expanded apically. Mentum weakly transverse, 1.5 times as broad as long; anterior margin weakly arcuate; ventral surface with horseshoe-like impression; prementum transverse; ligula parallel-sided; labial palps separated by distance about equal to width of palpiger; apical palpomere as long and as broad as penultimate one; submentum distinct.

Pronotum (Fig. 2F). With anterolateral angles rounded, scarcely produced anteriorly, not swollen with regular border; anterior and hind margin without border; lateral margin with entire border. Prothoracic hypomeron with weak, broad, concave area along anterior half of prothoracic lateral margin; notosternal suture weakly visible, simple; prosternal process (Fig. 2G) 0.55 times as broad as longest coxal diameter, its surface with lateral carinae complete, convergent and joined anteriorly forming a triangle; prosternum in front of coxa about 0.45 times as long as coxal longitudinal diameter at the same position; anterior margin continuing as weakly arcuate line, much more posterior than anterior pronotal margin; procoxal cavity distinctly transverse, without visible bordering line.

Pterothorax. Anterior margin of mesoventrite with complete raised border (Fig. 2G); mesoventral process at median length of coxa 1.25-1.30 times as broad as corresponding coxal diameter; mesometaventrite articulation with suture visible; junction angulate posteriorly. Scutellar shield transverse, triangular; surface punctate and setose. Elytra with sides subparallel; with lateral margins very narrow but entirely visible from above; surface with single size punctures (Fig. 2I), elytral epipleuron comparatively narrow, 1.5 times as wide as corresponding metaepisternum, incomplete apically (Fig. 2A), inner margin with border area narrow throughout and border line fading before base of elytron. Metaventrite with discrimen long but incomplete anteriorly; metaventral postcoxal lines distinctly separated at middle, laterally complete and recurved; metaepisternum with external process interlocking with fovea on elytron; metaepimeron indistinct.

LEGS. With trochanters angulately produced (Fig. 2A, G-H); tibiae without visible apical spurs; fore and mid tarsal claws appendiculate (Fig. 2C); metatarsal claws with quadrate basal tooth (Fig. 2D).

Abdomen (Figs 2H, 4A). With five ventrites, ventrite 6 partially visible; ventrite 1- 1.6 times as long as ventrite 2; abdominal postcoxal lines separate medially, recurved and complete anteriorly, deep, posteriorly almost reaches ventrite 2 ; hind margin of ventrite 5 covered with long setae and deeply emarginate; hind margin of ventrite 6 weakly emarginate, tergite VIII widely truncate apically (Fig. 4B).

Male terminalia And genitalia (Figs 4C, 5A-D). Sternite IX with central part membranous (Fig. 4C); apodeme of male sternum IX with its apical half rod-like, base of spiculum broadly widened. Penis base with outer arm reduced, inner well developed; penis apex as in Fig. 5A-B. Parameres (Fig. 5C-D) articulated with phallobase, well developed, simple and separated, slightly longer than penis guide, with apices covered with long setae; penis guide simple, subtriangular in inner view, without additional processes, with acute apex and lateral sides symmetrical throughout and pointed apex; tegminal strut simple, slightly expanded at apex.

Female. Not known. 


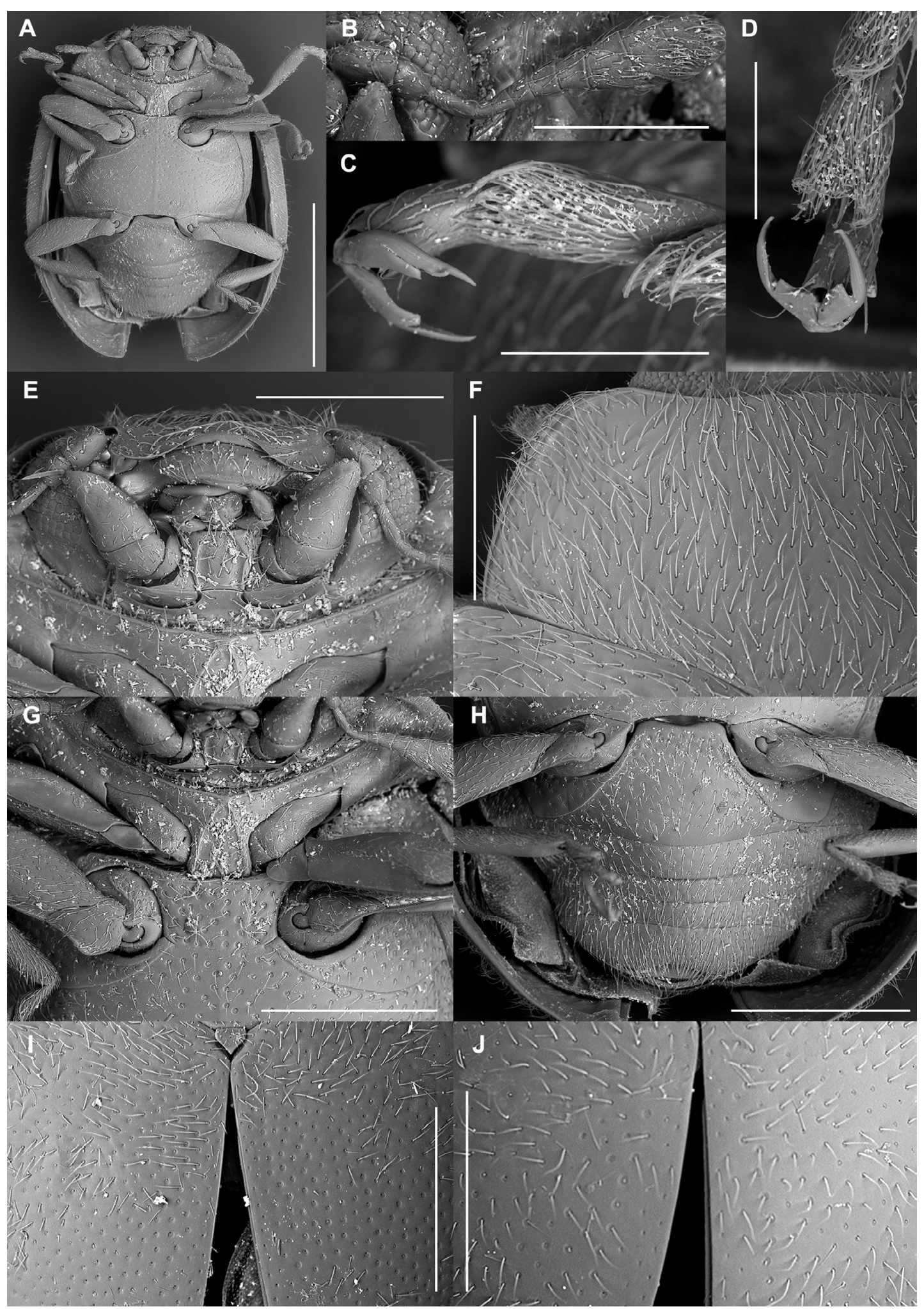

Fig. 2. SEM images of Rhyzobius spp. (holotypes). A-I. R. albinos sp. nov., ô (MNHN). J. R. atramentarius sp. nov., $\widehat{\jmath}(\mathrm{MNHN})$. A. Habitus, ventral. B. Antenna. C. Protarsal claws. D. Hind tarsal claws. E. Head, ventral. F. Pronotum. G. Pro-, meso- and metathorax, ventral. H. Abdomen, ventral. I-J. Details of elytral punctation. Scale bars: A $=1.00 \mathrm{~mm} ; \mathrm{B}=0.2 \mathrm{~mm} ; \mathrm{C}-\mathrm{D}=0.1 \mathrm{~mm} ; \mathrm{E}-\mathrm{F}=$ $0.3 \mathrm{~mm} ; \mathrm{G}=0.4 \mathrm{~mm} ; \mathrm{H}-\mathrm{J}=0.5 \mathrm{~mm}$. 


\section{Distribution}

Papua New Guinea: Mt Wilhelm.

Rhyzobius atramentarius sp. nov.

urn:1sid:zoobank.org:act:DF580E82-B342-4539-A42C-EB783E34A9FA

Figs $1 \mathrm{E}-\mathrm{H}, 2 \mathrm{~J}, 3 \mathrm{~A}-\mathrm{B}, \mathrm{D}, \mathrm{F}, \mathrm{H}, 4 \mathrm{D}-\mathrm{F}, 5 \mathrm{E}-\mathrm{I}$

\section{Diagnosis}

This species is most similar to $R$. amabilis Weise, 1918 and $R$. papuensis Tomaszewska, 2010, but can be distinguished from them by having a single apical spur on the mid and hind tibiae, and the prosternal process with carinae joined distinctly before the anterior prosternal margin and continuing anteriorly as a single carina (resembling an inverted wine glass). The shape of the prosternal carinae in $R$. atramentarius $\mathrm{sp}$. nov. is similar to $R$. serratus $\mathrm{sp}$. nov., but $R$. atramentarius $\mathrm{sp}$. nov. differs from $R$. serratus sp. nov. by having a single apical spur on the mid and hind tibiae, the eyes with distinct interfacetal setae, ventrite 5 in male not emarginate at apex and an indistinct metaepimeron.

\section{Etymology}

The specific epithet means 'inky' in Latin and refers to the body colouration of this species.

\section{Material examined}

\section{Holotype}

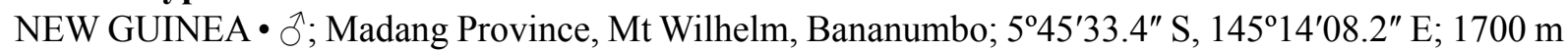
a.s.1.; 7-9 Nov. 2012; “06695-CoCocc Ibisca Niugini 2012”; FIT-MW1700-L-7/8-d14; plot 12, order 5212; MNHN.

\section{Paratypes}

NEW GUINEA - Madang Province - 1 đ; same collection data as for holotype; 1-3 Nov. 2012; “06678-CoCocc Ibisca Niugini 2012"; FIT-MW1700-L-4/8-d08; plot 12, order 10222; MNHN • 1 \%; same collection data as for holotype; 26-29 Oct. 2012; "02446-CoCocc Ibisca Niugini 2012"; FITMW1700-B-2/8-d03; plot 2, order 4308; MNHN • 1 o; Mt Wilhelm; 1200 m a.s.1.; 3-5 Nov. 2012; “18842-CoCocc Ibisca Niugini 2012”; FIT-MW1200-R-5/8-d10; plot 18, order 3059; MIZ.

\section{Type locality}

Papua New Guinea, Madang Province, Mt Wilhelm, Bananumbo.

\section{Description}

MeAsurements. Length 2.00-2.35 mm; TL/EW = 1.17; PL/PW =0.50; EL/EW =0.90-1.00.

Body (Figs 1E-G, 3A-B). Broadly oval, strongly convex dorsally, hemispherical, winged; black or blackish brown, predominantly with bluish metallic sheen; antennae, mouthparts, tarsi, ventrites 2-5 and ventrite 1 partially, brown. Dorsum with double pubescence consisting of appressed setae and sparse darker stiff bristles; dorsal pubescence forming weak wavy pattern on elytra; sparse elytral bristles present on lateral margins and apices only.

HEAD (Fig. 1H). Withdrawn into prothorax but with eyes partially visible externally; ventral antennal grooves distinctly circularly bent towards outer margin of eye. Eyes dorsally with inner orbits convergent, closer near vertex than anteriorly; ocular canthus extending slightly into eye; interocular distance 0.55 times as wide as head across eyes; interfacetal setae distinct. Antenna $0.70-0.73$ times as long as head 


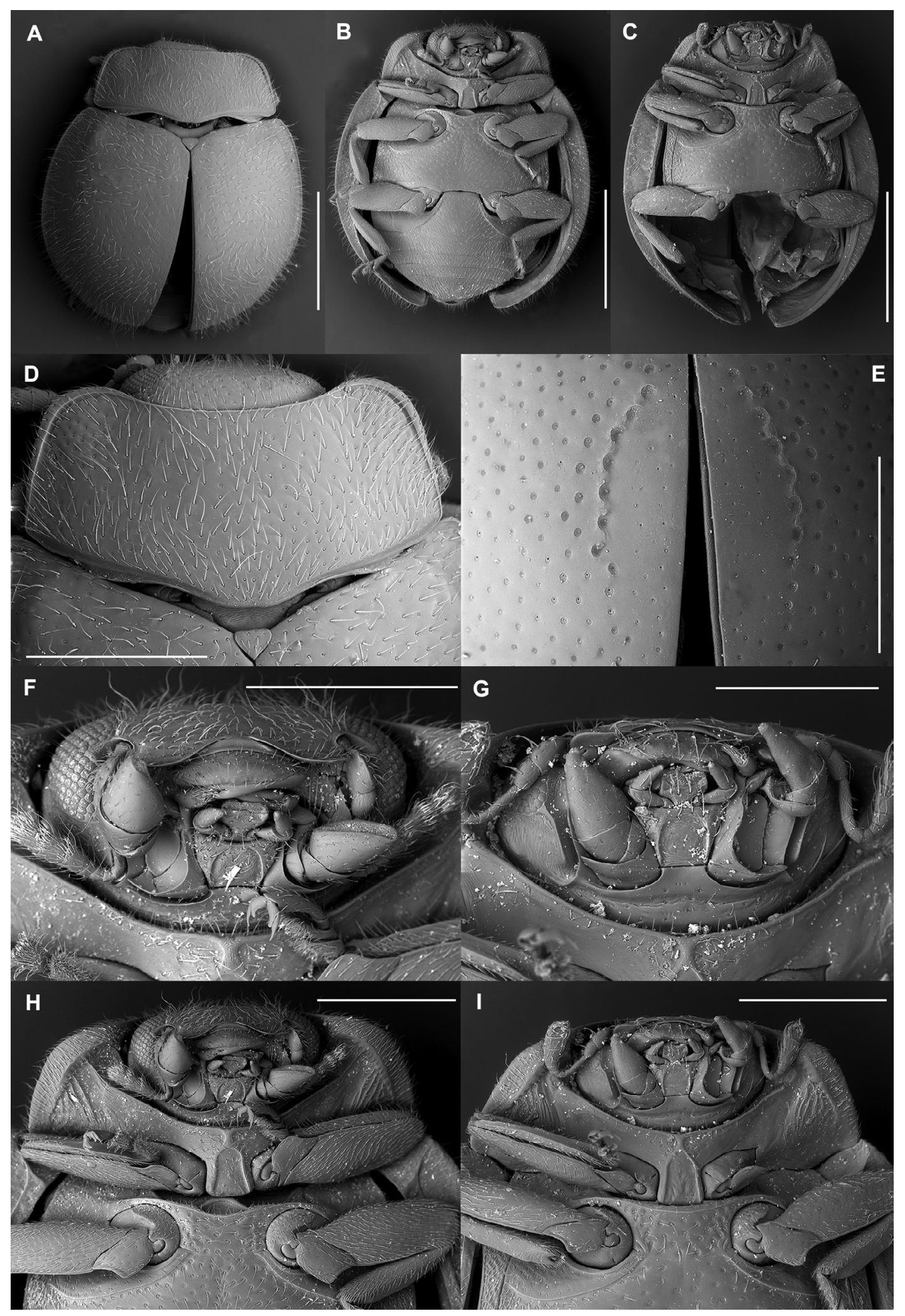

Fig. 3. SEM images of Rhyzobius spp. (holotypes). A-B, D, F, H. R. atramentarius sp. nov., ô (MNHN). C, E, G, I. Rhyzobius serratus sp. nov., O (MNHN). A. Habitus, dorsal. B-C. Habitus, ventral. D. Pronotum. E. Details of elytral punctation. F-G. Head, ventral. H-I. Pro-, meso- and metathorax, ventral. Scale bars: A-C $=1.0 \mathrm{~mm}$; D-E, H- I $=0.5 \mathrm{~mm} ; \mathrm{F}=0.4 \mathrm{~mm} ; \mathrm{G}=0.3 \mathrm{~mm}$. 
capsule width, composed of 11 antennomeres; scape swollen, 1.55-1.65 times as long as pedicel; pedicel distinctly narrower than scape, $1.20-1.25$ times as long as wide; antennomere 3- 2.72-2.75 times as long as wide, and about 2.25-2.50 times as long as antennomere 4; antennomere 4- 1.301.33 as long as 5; antennomeres 5 and 6 quadrate, antennomeres 7 and 8 slightly obconical. Antennal club consisting of 3 antennomeres, with two subterminal antennomeres asymmetrical; penultimate antennomere distinctly shorter than terminal one; terminal antennomere distinctly elongate, rounded apically. Clypeus with anterior margin distinctly emarginate, with lateral rounded lobes and median area membranous (Fig. 3F). Labrum truncate at apex. Maxilla with cardo transverse with outer angle reaching slightly outside of mouth cavity; terminal palpomere about as long as wide, weakly expanded apically. Labium with mentum strongly transverse, about 2 times as broad as long; anterior margin weakly arcuate; ventral surface with horseshoe-like impression; prementum transverse; ligula parallelsided; labial palps separated by distance about equal to width of palpiger; apical palpomere as long and as broad as penultimate one; submentum distinct.

Pronotum (Fig. 3D). With anterolateral angles rounded, scarcely produced anteriorly, not swollen but with distinct groove near angles; anterior and hind margin without border; lateral margin with entire border. Prothoracic hypomeron (Fig. $3 \mathrm{H}$ ) with broad, concave area along prothoracic lateral margin; notosternal suture distinct, simple; prosternal process 0.6 times as broad as longest coxal diameter, its surface with lateral carinae joined before anterior margin of prosternum and continuing anteriorly as a single carina; prosternum in front of coxa about 0.55 times as long as coxal longitudinal diameter at the same position; anterior margin continuing as weakly arcuate line, much more posterior than anterior pronotal margin; procoxal cavity distinctly transverse, without visible bordering line.

Pterothorax. Anterior margin of mesoventrite (Fig. 3H) with complete raised border; mesoventral process at median length of coxa about 1.5 times as broad as corresponding coxal diameter; mesometaventrite articulation with suture visible; junction somewhat angulate posteriorly. Scutellar shield transverse, triangular; surface punctate and setose. Elytra (Fig. 3A) with lateral margins narrow but entirely visible from above; elytral epipleuron (Fig. 3B) incomplete apically, 2.7-3.0 times as wide as corresponding metaepisternum, inner margin with border area widening towards elytral base and border line upturned outwardly near base of elytron; elytral surface covered with middle size punctures, only along suture there is a row of smaller punctures (Fig. 2J). Metaventrite with complete discrimen; metaventral postcoxal lines (Fig. $3 \mathrm{H}$ ) distinctly separated at middle, recurved and laterally complete; metaepisternum with external process interlocking with fovea on elytron; metaepimeron indistinct.

LEGS. With all trochanters angulately produced (Fig. 3B, H); fore tibia without spurs, mid and hind tibia with single apical spur; fore and mid tarsal claws in male appendiculate; metatarsal claws in male and claws in female with subquadrate basal tooth.

ABDOMEN (Fig. 4D). With five ventrites in both sexes; ventrite 1- 1.6 times as long as ventrite 2; abdominal postcoxal lines separate medially, recurved and complete anteriorly, deep, posteriorly almost reach hind margin of ventrite 1 ; ventrite 5 in female distinctly longer than 4 , with hind margin arcuate and smooth; ventrite 5 in male simply setose with hind margin narrowly truncate or scarcely emarginate medially; female sternite VIII with hind margin arcuate, tergite VIII rounded; hind margin of male sternite VIII emarginate (Fig. 4E), tergite VIII widely truncate apically.

Male terminalia and genitalia (Figs 4F, 5E-H). Male genital segment with sternite IX with central part membranous (Fig. 4F); apodeme of male sternum IX with its apex widened, and base of spiculum widened, partially submembranous with small sclerotized, lateral sclerites. Penis base with outer arm reduced, inner arm well developed; penis apex as in Fig. 5E-F. Parameres (Fig. 5G-H) articulated with phallobase, well developed, simple and separated, distinctly longer than penis guide, densely setose 

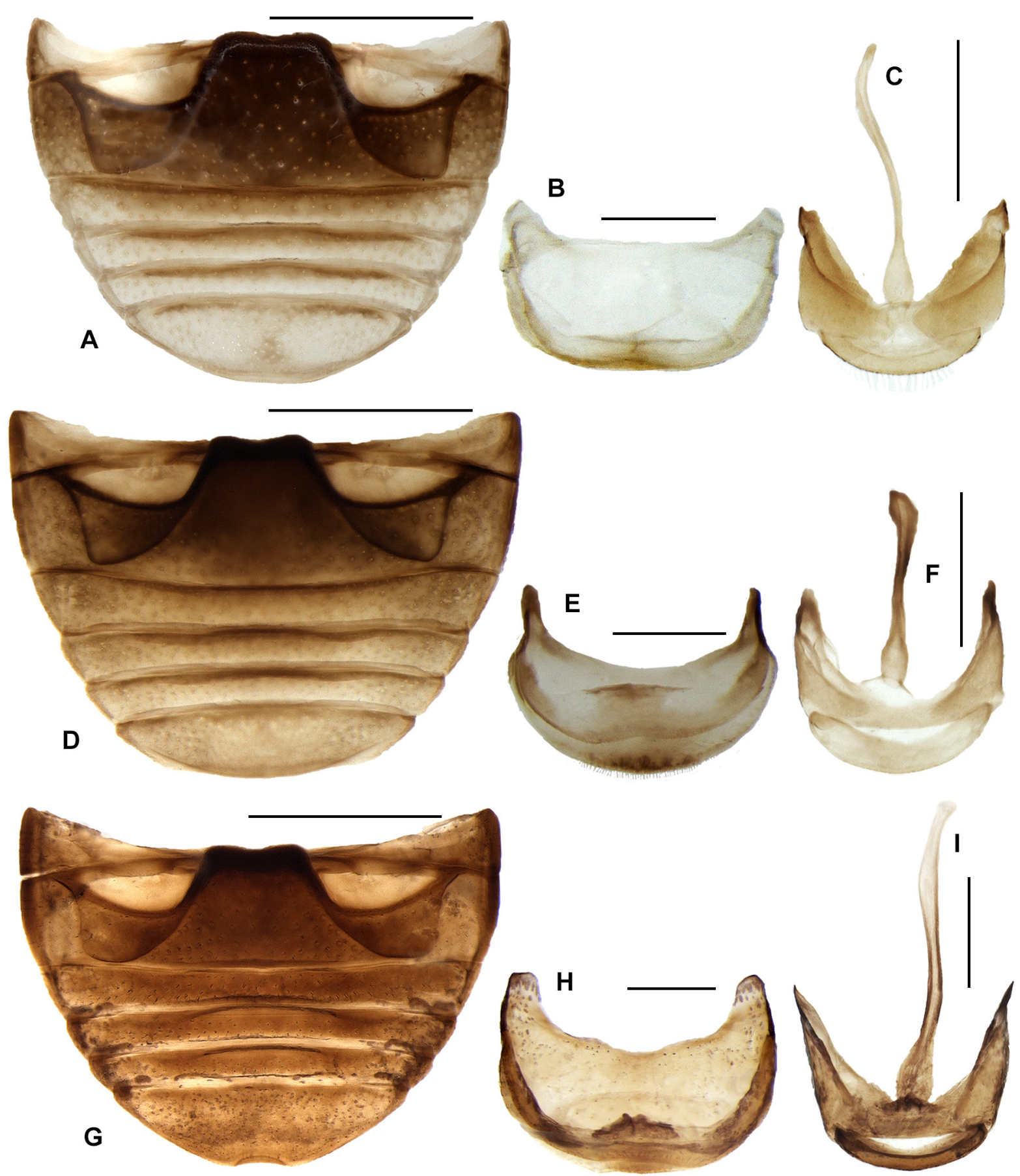

Fig. 4. Abdomens and male terminalia of Rhyzobius spp. A-C. R. albinos sp. nov. D-F. R. atramentarius sp. nov. G-I. R. serratus sp. nov. A, D, G. Abdomen. B, E, H. Abdominal segment VIII, ventral. C, F, I. Male genital segment, dorsal. Scale bars: A, D, G $=0.5 \mathrm{~mm}$; B-C, E-F, H-I $=0.2 \mathrm{~mm}$. 
along at least half of their length, with apices covered with simple, long setae; penis guide simple, subtriangular, without additional processes, with lateral sides symmetrical and pointed apex; tegminal strut simple.

Female genitalia (Fig. 5I). Proctiger (T10) reduced, small, submembranous; styli strongly reduced and hardly visible; infundibulum absent; sperm duct short, uniform in diameter, spermatheca without clear nodulus and ramus, spermathecal accessory gland adjacent to sperm duct.

\section{Distribution}

Papua New Guinea: Mt Wilhelm.

Rhyzobius serratus sp. nov. urn:lsid:zoobank.org:act:96A5BE00-3CB9-4A99-AEDE-73284A171644

Figs 1I-L, 3C, E, G, I, 4G-I, 5J-M

\section{Diagnosis}

This species is similar to R. amabilis Weise, 1918 and R. papuensis Tomaszewska, 2010, but it can be distinguished from them by having elytra with a distinct, oval area along the mid length of the elytral suture covered with only small punctures surrounded by rows of coarse macropunctures (similar to $R$. weiri Tomaszewska, 2010), and the prosternal process with carinae joined before the anterior prosternal margin and continuing anteriorly as a single carina. This shape of prosternal carinae is similar to that in $R$. atramentarius sp. nov., but $R$. serratus sp. nov. differs from it by lacking of tibial spurs, the eyes without interfacetal setae, ventrite 5 in the male with the posterior margin emarginate and by having distinct metaepimeron.

\section{Etymology}

The name of this species derives from the Latin and refers to the serrate outer surface of the penis guide.

\section{Material examined}

\section{Holotype}

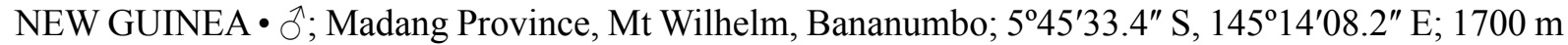
a.s.1.; 30 Oct.-1 Nov. 2012; “06727-CoCocc Ibisca Niugini 2012”; FIT-MW1700-S-3/8-d06; plot 19, order 10233; MNHN.

\section{Type locality}

Papua New Guinea, Madang Province, Mt Wilhelm, Bananumbo.

\section{Description}

MEASUREMENTs. Length $2.30 \mathrm{~mm} ; \mathrm{TL} / \mathrm{EW}=1.21 ; \mathrm{PL} / \mathrm{PW}=0.45 ; \mathrm{EL} / \mathrm{EW}=1.0$.

Body (Fig. 1I-K). Broadly oval, strongly convex dorsally, hemispherical, winged; black and shiny; antennae, mouthparts, tarsi and abdominal ventrites (except ventrite 1) pale brown. Dorsum with double pubescence consisting of appressed setae and sparse darker stiff bristles distinct along elytral lateral margins only; dorsal pubescence not forming pattern on elytra.

HEAD (Fig. 1L). Withdrawn into prothorax with eyes partially visible externally; ventral antennal grooves distinctly circularly bent towards outer margin of eye. Eyes dorsally with inner orbits convergent, closer near vertex than anteriorly; ocular canthus extending slightly into eye; interocular distance 0.53 times as wide as head across eyes; interfacetal setae indistinct. Antenna composed of 11 antennomeres, 
about 0.75 times as long as head capsule width; scape large, swollen, 1.55 times as long as pedicel; pedicel barrel-shaped, narrower than scape, 1.3 times as long as wide; antennomere 3-2.30 times as long as wide, and about 2.5 times as long as 4; antennomere 4- 1.15 times as long as 5; antennomeres 5 and 6 quadrate, antennomere 7 obconical, at base about 0.75 times as wide as at apex and about 1.2 times as long as antennomere 6 . Antennal club consisting of 3 antennomeres, with two subterminal segments asymmetrical; antennomere 9 as long as antennomere 10 and distinctly shorter than terminal antennomere; terminal antennomere distinctly elongate, rounded apically. Anterior clypeal margin distinctly emarginate, with rounded lateral lobes and with median area membranous. Labrum truncate at apex. Maxilla with cardo transverse with outer angle reaching slightly outside of mouth cavity (Fig. 3G); terminal palpomere 1.1 times as long as wide, weakly expanded apically. Mentum transverse, about 1.5 times as wide as long; anterior margin almost straight; ventral surface with horseshoe-like impression; prementum as long as broad; ligula parallel-sided; labial palps separated by distance about equal to width of palpiger; apical palpomere as long and as broad as penultimate one; submentum distinct.

Pronotum. With anterolateral angles rounded, not swollen, but with distinct groove near angles; anterior and hind margin without border; lateral margin with entire border. Prothoracic hypomeron (Fig. 3I) with broad, concave area along anterior half of prothoracic lateral margin; notosternal suture distinct, simple; prosternal process 0.6 times as broad as longest coxal diameter, its surface with carinae joined before apex and continuing anteriorly as single carina; prosternum in front of coxa about 0.65 times as long as coxal longitudinal diameter at the same position; anterior margin continuing as weakly arcuate line, much more posterior than anterior pronotal margin; procoxal cavity distinctly transverse, without visible bordering line.

Pterothorax. Anterior margin of mesoventrite (Fig. 3I) with complete raised border; mesoventral process at median length of coxa about 1.20 times as broad as corresponding coxal diameter; mesometaventrite articulation with suture visible; junction angulate posteriorly. Scutellar shield transverse, triangular, surface punctate and setose. Elytra with lateral margins narrow, but entirely visible from above; surface with distinct, oval area with small punctures along mid length of elytral suture surrounded by rows of coarse macropunctures (Fig. 3E). Elytral epipleuron incomplete apically, 2.5 times as wide as corresponding metaepisternum, inner margin with border area narrow throughout and border line fading before base of elytron. Metaventrite coarsely punctate, with complete discrimen; metaventral postcoxal lines distinctly separated at middle, recurved and complete laterally; metaepisternum with external process interlocking with fovea on elytron; metaepimeron distinct, visible ventrally.

LEGS. With trochanters angulately produced (Fig. 3C, I); tibiae without visible apical spurs; fore and mid tarsal claws in male appendiculate, holotype specimen misses metatibiae and tarsi.

AвDOMEN (Fig. 4G). With five ventrites; ventrite 1- 1.6 times as long as ventrite 2; abdominal postcoxal lines separate medially, recurved and complete anteriorly, deep, posteriorly nearly reaching anterior margin of ventrite 2; ventrite 5 simply setose, hind margin narrowly emarginate; hind margin of sternite VIII weakly emarginate (Fig. 4H), tergite VIII rounded.

Male terminalia and genitalia (Figs 4I, 5J-M). Male genital segment with sternite IX with central part membranous (Fig. 4I); apodeme of male sternum IX rod-like, and base of spiculum widened, membranous. Penis base with outer arm obsolete, inner arm well developed; penis apex as in Fig. 5J-K. Parameres (Fig. 5L-M) articulated with phallobase, well developed, simple and separated, comparatively narrow, about 0.9 times as long as penis guide, with apices covered with simple setae; penis guide broad, without additional processes with outer margin serrate along apical half, widest at about apical sixth, with lateral sides sinuate but symmetrical throughout, with upturned apex; tegminal strut simple. 


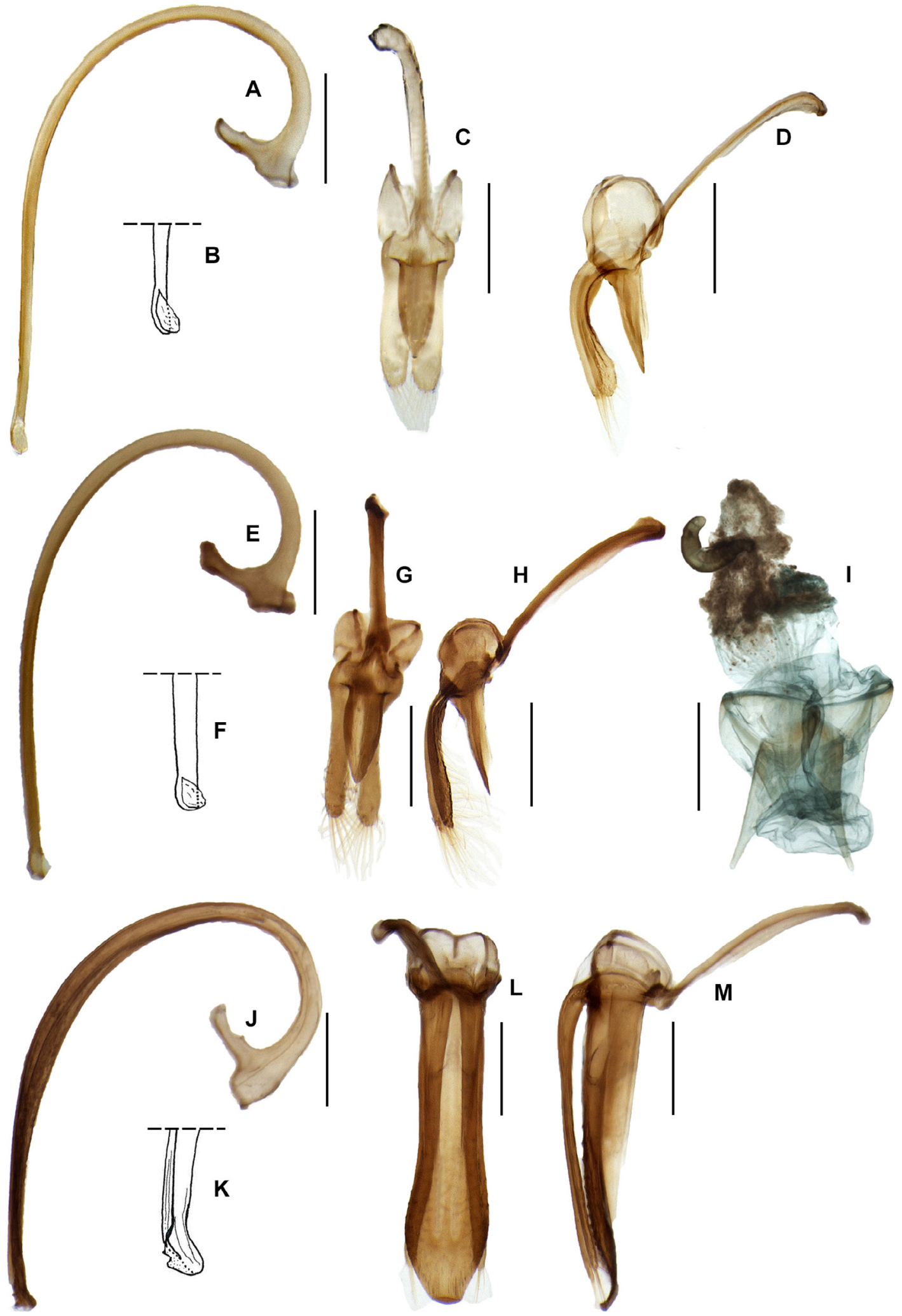

Fig. 5. Male and female genitalia of Rhyzobius spp. A-D. $R$. albinos sp. nov. E-I. $R$. atramentarius sp. nov. J-M. R. serratus sp. nov. A, E, J. Penis, lateral. B, F, K. Apex of penis. C, G, L. Tegmen, inner view. D, H, M. Tegmen, lateral. I. Female genitalia. Scale bars: $0.2 \mathrm{~mm}$. 
Female. Not known.

\section{Distribution}

Papua New Guinea: Mt Wilhelm.

An updated key to species of Rhyzobius from New Guinea (based on Tomaszewska, 2010)

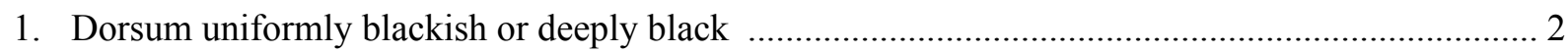

- Dorsum bicoloured (black and brown, orange or yellowish) ....................................................... 7

2. Elytra with strongly intensive, three-coloured (green, violet and blue) metallic sheen

R. metallicus Tomaszewska, 2010

- Elytra with moderately intensive, unicoloured metallic sheen or without metallic sheen ............... 3

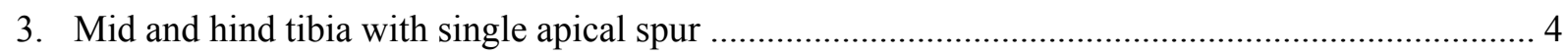

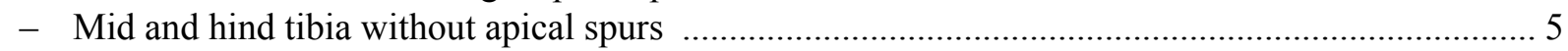

4. Body large (2.85-3.65 mm long); elytra coarsely punctate; prosternal carinae subparallel, joined roundly before anterior prosternal margin

R. iracildae Tomaszewska, 2010

- Body smaller (2.00-2.35 mm long); elytra less coarsely punctate; prosternal carinae joined before anterior prosternal margin and continuing anteriorly as a single carina .... R. atramentarius sp. nov.

5. Body large and oval; prosternal carinae complete and separate

R. amabilis Weise, 1918

- Body mostly smaller and more elongate; prosternal carinae joined anteriorly

6. Pronotum distinctly swollen towards anterolateral angles; prosternal carinae complete, joined anteriorly in form of triangle; prothoracic hypomeron with short crescent shaped groove perpendicular to notosternal suture

R. papuensis Tomaszewska, 2010

- Pronotum not swollen towards anterolateral angles; prosternal carinae joined before anterior margin of prosternum and continuing anteriorly as a single carina, forming bell-like shape; prothoracic hypomeron with broad concave area along anterior half of prothoracic lateral margin

R. serratus sp. nov.

7. Elytra black with small, preapical, yellowish, round oval spot on each elytron; pronotum black .....

R. bipunctatus Tomaszewska, 2010

- Elytra black without spots, or with brown apex; pronotum brown or bicoloured (black and brown)

8. Ventral antennal grooves reaching beyond posterior margin of eyes, straight; pronotum with regular border

- Ventral antennal grooves distinctly circularly bent towards outer margin of eye; pronotum usually with at least weak groove near anterior angles

9. Prosternal process smooth, not carinate; elytra black with yellow apices

R. jaya Tomaszewska, 2010

- Prosternal carinae joined roundly before prosternal margin and continuing anteriorly as single carina; elytra entirely black

R. leucochaetus Tomaszewska, 2010

10. Pronotum black or dark brown with at least lateral margins light brown ......................................11

- Pronotum brown, sometimes weakly infuscate at base 
11. Pronotal lateral margins distinctly swollen towards anterolateral angles of pronotum and with deep groove near angles; prosternal process with carinae joined before anterior margin of prosternum and continuing anteriorly as single carina

R. poorani Tomaszewska, 2010

- Pronotal lateral margins not swollen, without groove near anterolateral angles of pronotum; prosternal process with complete carinae, joined anteriorly in form of triangle

R. albinos sp. nov.

12. Mid and hind tibia with single apical spur; prosternal carinae joined roundly before anterior margin of prosternum and continuing anteriorly as single carina

R. gonzalezi Tomaszewska, 2010

- Mid and hind tibia without apical spurs; prosternal carinae separate throughout their length or joined but not continuing anteriorly as single carina

13. Body stronger convex in dorsal aspect; elytra mostly black with violet metallic sheen, apex somewhat paler; prosternal carinae complete and separated; male ventrite 5 with admedian setose patches, apical margin narrowly truncate

R. violaceus Tomaszewska, 2010

- Body less convex; elytra entirely black with cupreous metallic sheen; prosternal carinae joined roundly just before prosternal margin; male ventrite 5 simply setose and with apical margin rounded

R. luciae Tomaszewska, 2010

\section{Discussion}

The New Guinean Rhyzobius fauna was represented until the present study by 11 species (Tomaszewska 2010). All of them are predominantly montane species, except $R$. papuensis, which can also be found in lowlands $(<1200 \mathrm{~m}$ a.s.1.). The three new species here described are also montane species and inhabit middle elevations. Rhyzobius albinos sp. nov. is a montane forest species occurring at altitudes between 1200 and $2200 \mathrm{~m}$ a.s.l. in forest types like "mixed lowland forest" and "lower- to mid- montane forest". Rhyzobius atramentarius sp. nov. was found at altitudes of 1200-1700 m a.s.l. in an elevational zone classified as "mixed lowland forest" and "lower montane forest", and $R$. serratus sp. nov. was found at an altitude of $1700 \mathrm{~m}$ a.s.1. in an elevational zone classified as "lower montane forest". Classification of elevational zones and altitudes corresponding to them according to Johns (1982) and Leponce et al. (2016).

Considering that 11 species of this genus were previously known from the whole island, the finding of three new species in this one place alone may indicate that the local fauna is only moderately known, and it is probable that more species will be found in the future at different localities.

\section{Acknowledgements}

We would like to thank Carl Wardhaugh (Scion, Rotorua, New Zealand) for a loan of the material for this study and Magdalena Kowalewska-Groszkowska (MIZ) for help with SEM images. We thank two anonymous reviewers for their valuable comments and corrections on the manuscript.

This study was conducted in the framework of "Our Planet Reviewed Papua-New Guinea 2012-2013" set up by Pro-Nature International, the National Museum of Natural History (MNHN, France), the Institut de Recherche pour le Développement (IRD, France) in partnership with the Royal Belgian Research Center, the University of Papua New Guinea, and the Divine Word University of Madang and with core funding of Prince Albert II of Monaco Foundation, the Fondation d'entreprise EDF, the Fonds Pacifique, Spiecapag, Entrepose Contracting, the New-Caledonia Government, the Reef Foundation, FNRS (Belgium) and the Belgian National Lottery. All participants to this collective project, part of the IBISCA experts network patroned here by prof. R.K. Kitching, are thanked for their contribution. 


\section{References}

Casey T.L. 1899. A revision of the American Coccinellidae. Journal of the New York Entomological Society 7 (2): 71-169.

Crotch G.R. 1874. A Revision of the Coleopterous Family Coccinellidae. E.W. Janson, London. https://doi.org/10.5962/bhl.title.8975

Ganglbauer L. 1899. Die Käfer von Mitteleuropa. Die Käfer der österreichisch-ungarischen Monarchie, Deutschlands, der Schweiz, sowie des französischen und italienischen Alpengebietes. Familienreihe Clavicornia. Sphaeritidae, Ostomidae, Byturidae, Nitidulidae, Cucujidae, Erotylidae, Phalacridae, Thorictidae, Lathridiidae, Mycetophagidae, Colydiidae, Endomychidae, Coccinellidae. Vol. III, part 2. C. Gerold's Sohn, Wien.

Johns R.J. 1982. Plant zonation. In: Gressit J.L. (ed.) Biogeography and Ecology of New Guinea: 309330. Dr W. Junk Publishers, The Hague. https://doi.org/10.1007/978-94-009-8632-9_13

Leponce M., Novotny V., Pascal O., Robillard T., Legendre F., Villemant C., Munzinger J., Molino J.-F., Drew R., Odegaard F., Schmidl J., Tishechkin A., Sam K., Bickel D., Dahl C., Damas K., Fayle T.M., Gewa B., Jacquemin J., Keltim M., Klimes P., Koane B., Kua J., Mantilleri A., Mogia M., Molem K., Moses J., Nowatuo H., Orivel J., Pintaud J.-C., Roisin Y., Sam L., Siki B., Soldati L., Soulier-Perkins A., Tulai S., Yombai J., Wardhaugh C. \& Basset Y. 2016. Land module of Our Planet Reviewed - Papua New Guinea: aims, methods and first taxonomical results. In: Robillard T., Legendre F., Villemant C. \& Leponce M. (eds) Insects of Mount Wilhelm, Papua New Guinea: 11-48. Muséum national d'histoire naturelle, Paris.

Mulsant E. 1850. Species de coléoptères trimères sécuripalpes. Annales des Sciences physiques et naturelles, d'Agriculture et d'Industrie de Lyon, Série 2, 2 (2): 451-1104.

https://doi.org/10.5962/bhl.title.8953

Poorani J. \& Ślipiński A. 2009. A revision of the genera Scymnodes Blackburn and Apolinus Pope et Lawrence (Coleoptera: Coccinellidae). Annales Zoologici 59: 549-584.

https://doi.org/10.3161/000345409X484946

Poorani J. \& Ślipiński A. 2010. A review of Rhynchortalia Crotch (Coleoptera: Coccinellidae: Ortaliinae). Zootaxa 2423: 25-43. https://doi.org/10.11646/zootaxa.2423.1.2

Poorani J., Ślipiński A. \& Booth R.G. 2014. A review of the genus Cryptolaemus Mulsant (Coleoptera: Coccinellidae: Coccinellinae: Coccidulini) from New Guinea. Annales Zoologici 64: 613-654.

https://doi.org/10.3161/000345414X685929

Robertson J.A., Ślipiński A., Moulton M., Shockley F.W., Giorgi A., Lord N.P, McKenna D.D., Tomaszewska W., Forrester J., Miller K.B., Whiting M.F. \& McHugh J.V. 2015. Phylogeny and classification of Cucujoidea and the recognition of a new superfamily Coccinelloidea (Coleoptera: Cucujiformia). Systematic Entomology 40: 745-778. https://doi.org/10.1111/syen.12138

Seago A.E., Giorgi J.A., Li J. \& Ślipiński A. 2011. Phylogeny, classification and evolution of ladybird beetles (Coleoptera: Coccinellidae) based on simultaneous analysis of molecular and morphological data. Molecular Phylogenetics and Evolution 60: 137-151. https://doi.org/10.1016/j.ympev.2011.03.015

Ślipiński A. 2007. Australian Ladybird Beetles (Coleoptera: Coccinellidae). Their Biology and Classification. Australian Biological Resources Study, Canberra.

Ślipiński A. \& Tomaszewska W. 2010. Coccinellidae Latreille, 1802. In: Leschen R.A.B., Beutel R.G. \& Lawrence J.F. (eds) Handbook of Zoology, Arthropoda: Insecta. Coleoptera, Beetles. Volume 2: Morphology and Systematics (Elateroidea, Bostrichiformia, Cucujiformia partim): 454-472. Walter de Gruyter GmbH \& Co. KG., Berlin/New York. https://doi.org/10.1515/9783110911213.454 
Stephens J.F. 1829. A Systematic Catalogue of British Insects: Being an Attempt to Arrange all the Hitherto Discovered Indigenous Insects in Accordance with their Natural Affinities. Containing also the References to Every English writer on Entomology, and to the Principal foreign Authors. With all the Published British Genera to the Present Time. Part 1. Baldwin and Cradock, London. https://doi.org/10.5962/bhl.title.8987

Szawaryn K. 2018. Missing geographic link: minute lady beetles (Coleoptera: Coccinellidae: Microweiseinae) from Mount Wilhelm, New Guinea. Acta Entomologica Musei Nationalis Pragae 58 (1): $117-236$.

Tomaszewska W. 2010. Rhyzobius Stephens 1829 (Coleoptera: Coccinellidae), a Revision of the World Species. Fauna Mundi 2, Natura optima dux Foundation, Warsaw.

Manuscript received: 25 February 2020

Manuscript accepted: 22 June 2020

Published on: 28 July 2020

Topic editor: Nesrine Akkari

Section editor: Max Barclay

Desk editor: Pepe Fernández

Printed versions of all papers are also deposited in the libraries of the institutes that are members of the EJT consortium: Muséum national d'histoire naturelle, Paris, France; Meise Botanic Garden, Belgium; Royal Museum for Central Africa, Tervuren, Belgium; Royal Belgian Institute of Natural Sciences, Brussels, Belgium; Natural History Museum of Denmark, Copenhagen, Denmark; Naturalis Biodiversity Center, Leiden, the Netherlands; Museo Nacional de Ciencias Naturales-CSIC, Madrid, Spain; Real Jardín Botánico de Madrid CSIC, Spain; Zoological Research Museum Alexander Koenig, Bonn, Germany; National Museum, Prague, Czech Republic. 